\title{
ANALISA KENYAMANAN PADA KENDARAAN MULTIGUNA PEDESAAN DENGAN PEMODELAN 8 DOF
}

\author{
Nanda Pranandita \\ Politeknik Manufaktur Negeri Bangka Belitung \\ Jurusan Teknik Mesin Program Studi Perawatan dan Perbaikan Mesin \\ Kawasan Industri Airkantung \\ Sungailiat, Telp.0717-93586 \\ Fax.0717-93585, \\ nda akano@yahoo.co.id
}

\begin{abstract}
Vehicle suspension system is an important part to minimize the vibration of the vehicle caused by road unevenness. Ideal conditions would be difficult to obtain, especially in rural areas with uneven road conditions. Analysis of passive suspension system in this study is expected to explain the level of comfort in riding Rural Multipurpose Vehicles. Full car modelling with 1 DOF riders used in this study, simulated using numerical simulation software. Excitation roads used in the form of a sinusoidal wave with an amplitude of $0.05 \mathrm{~m}$ and a wavelength of $0.5 \mathrm{~m}$. Analysis carried out on the comfort of the vertical acceleration response received driver's head. Based on the simulation results showed that by using a constant speed between $20-40 \mathrm{~km} / \mathrm{h}$, the vehicle will be comfortable driving for more than 2.5 hours.
\end{abstract}

Keywords: suspension system, ISO 2631, full car, numeric simulation

\begin{abstract}
Abstrak
Sistem suspensi kendaraan merupakan bagian penting untuk meminimalisasi getaran pada kendaraan yang diakibatkan ketidak rataan jalan. Kondisi ideal tentunya akan sulit didapatkan, apalagi di daerah pedesaan dengan kondisi jalan yang tidak rata. Analisa sistem suspensi pasif pada penelitian ini diharapkan dapat menjelaskan tingkat kenyamanan dalam mengendarai Kendaraan Multiguna Pedesaan. Pemodelan full car dengan 1 DOF pengendara yang digunakan pada penelitian ini, disimulasikan menggunakan software simulasi numerik. Eksitasi jalan yang digunakan berupa gelombang sinusoidal dengan amplitudo 0,05 $\mathrm{m}$ dan panjang gelombang 0,5 $\mathrm{m}$. Analisa kenyamanan dilakukan pada respon percepatan vertikal yang diterima kepala pengendara. Berdasarkan hasil simulasi didapatkan bahwa pada dengan menggunakan kecepatan konstan antara $20-40 \mathrm{~km} / \mathrm{jam}$, kendaraan akan nyaman dikendarai selama lebih dari 2,5 jam.
\end{abstract}

Kata kunci: sistem suspensi, ISO 2631, full car, simulasi numerik

\section{PENDAhULUAN}

Perkembangan industri otomotif mengalami kemajuan yang sangat pesat. Mobil merupakan salah satu alat transportasi yang banyak digunakan untuk mendukung mobilitas. Salah satu faktor penting yang menjadi pertimbangan konsumen dalam memilih mobil, yaitu faktor kenyamanan mobil yang akan digunakan. Mobil dengan tingkat kenyamanan yang rendah, akan mengakibatkan pengendara cepat mengalami kelelahan.

Menurut data KORLANTAS POLRI, mobil menyumbang sekitar $14 \%$ dari jumlah kecelakaan yang terjadi beberapa tahun terakhir [3]. Salah satu faktor yang dapat menyebabkan kecelakaan tersebut adalah kelelahan pengemudi. Sebagai upaya untuk mengurangi tingkat kecelakaan mobil yang 
dipengaruhi tingkat kelelahan pengemudi, maka diperlukan adanya analisa kenyamanan pada sebuah mobil. Analisa kenyamanan tersebut adalah ketahanan pengemudi untuk mengendarai kendaraan.

Pada penelitian ini, terfokus pada analisa respon percepatan vertikal yang dialami pengendara. Penelitian ini mengacu pada penelitian sebelumnya mengenai redesain sistem suspensi dengan menggunakan pemodelan half car. Pada penelitian tersebut, dapat diketahui kenyamanan dari pergerakan bouncing dan pitching. Berbeda halnya dengan penelitian ini, dengan menggunakan pemodelan full car dapat diketahui analisa kenyamanan akibat pengaruh pergerakan rolling kendaraan.

\section{METODE PENELITIAN}

Langkah-langkah penelitian yang digunakan pada penelitian ini ditunjukkan Gambar 1.
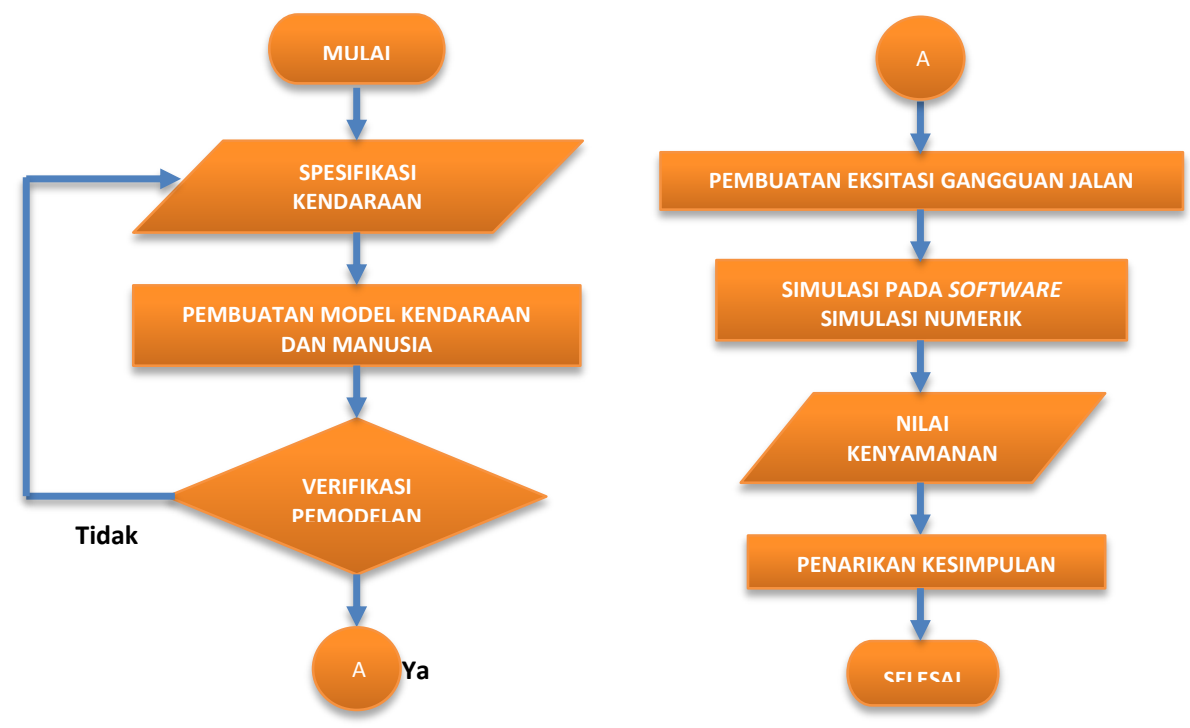

Gambar 1. Diagram Alir Penelitian

\subsection{Spesifikasi Kendaraan}

Data spesifikasi yang ditunjukkan Tabel 1 merupakan data spesifikasi Toyota Fortuner yang digunakan pada penelitian ini.

\subsection{Pembuatan Pemodelan Kendaraan dan Manusia}

Pemodelan kendaraan dan manusia pada penelitian ini menggunakan model full car, seperti yang ditunjukkan Gambar 2.

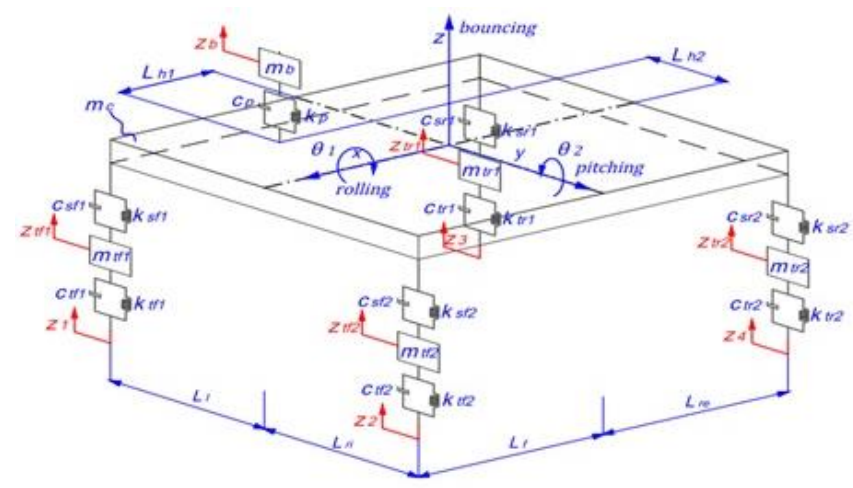

Gambar 2. Pemodelan Full Car dengan 1 DOF Pengendara 
Tabel 1. Spesifikasi Kendaraan Multiguna Pedesaan [2]

\begin{tabular}{l|l}
\hline \multicolumn{2}{l}{ Dimensi } \\
\hline Jarak antara sumbu roda depan dan belakang $(\mathrm{L})$ & $2590 \mathrm{~mm}$ \\
\hline Jarak sumbu roda depan ke CoG $\left(\mathrm{L}_{\mathrm{f}}\right)$ & $1560,30 \mathrm{~mm}$ \\
\hline Jarak sumbu roda belakang ke CoG $\left(\mathrm{L}_{\mathrm{re}}\right)$ & $1029,69 \mathrm{~mm}$ \\
\hline Jarak sumbu roda kanan ke CoG $\left(\mathrm{L}_{\mathrm{ri}}\right)$ & $570 \mathrm{~mm}$ \\
\hline Jarak sumbu roda kiri ke CoG $\left(\mathrm{L}_{\mathrm{l}}\right)$ & $605 \mathrm{~mm}$ \\
\hline Jarak CoG pengendara ke CoG kendaraan 1( $\left.\mathrm{L}_{\mathrm{h} 1}\right)$ & $447 \mathrm{~mm}$ \\
\hline Jarak CoG pengendara ke CoG kendaraan 2( $\left.\mathrm{L}_{\mathrm{h} 2}\right)$ & $337,5 \mathrm{~mm}$ \\
\hline Jarak CoG ke ground & $803,836 \mathrm{~mm}$ \\
\hline Massa Kendaraan & $1650 \mathrm{~kg}$ \\
\hline Massa total (W) & \\
\hline Suspensi & $53024,26015 \mathrm{~N} / \mathrm{m}$ \\
\hline Kekakuan pegas suspensi depan $\left(\mathrm{k}_{\mathrm{sf}}\right)$ & $40630,38127 \mathrm{~N} / \mathrm{m}$ \\
\hline Kekakuan pegas suspensi belakang $\left(\mathrm{k}_{\mathrm{sr}}\right)$ & $2675,5 \mathrm{~N} / \mathrm{m} . \mathrm{s}$ \\
\hline Konstanta redaman suspensi depan $\left(\mathrm{c}_{\mathrm{sf}}\right)$ & $2342 \mathrm{~N} / \mathrm{m} . \mathrm{s}$ \\
\hline Konstanta redaman suspensi belakang $\left(\mathrm{C}_{\mathrm{sr}}\right)$ & \\
\hline Ban & $265 / 65 \mathrm{R} 13$ \\
\hline Tipe ban & $\mathrm{Radial}$ \\
\hline Jenis ban & $265 \mathrm{~mm}$ \\
\hline Lebar ban & $50 \mathrm{~kg}$ \\
\hline Massa ban & $221973,4385 \mathrm{~N} / \mathrm{m}$ \\
\hline Kekakuan ban $\left(\mathrm{k}_{\mathrm{t}}\right)$ & $3430 \mathrm{~N} / \mathrm{m} . \mathrm{s}$ \\
\hline Konstanta redaman ban $\left(\mathrm{C}_{\mathrm{t}}\right)$ &
\end{tabular}

Berdasarkan pemodelan pada Gambar 2, dapat dituliskan free body diagram-nya sebagai berikut: $\sum F_{z}=m_{c} \cdot \ddot{Z}$ (Bouncing) (Sprung mass)

$m_{c} \cdot \ddot{z}=-k_{s f 1}\left(z-z_{t 1}-L_{f} \cdot \theta_{2}-L_{r i} \cdot \theta_{1}\right)-k_{s f 2}\left(z-z_{t 2}-L_{f} \cdot \theta_{2}+L_{l} \cdot \theta_{1}\right)-k_{s r 1}\left(z-z_{t 3}+L_{r e}\right.$. $\left.\theta_{2}+L_{r i} \cdot \theta_{1}\right)-k_{s r 2}\left(z-z_{t 4}+L_{r e} \cdot \theta_{2}-L_{l} \cdot \theta_{1}\right)-c_{s f 1}\left(\dot{z}-\dot{z}_{t 1}-L_{f} \cdot \dot{\theta}_{2}-L_{r i} \cdot \dot{\theta}_{1}\right)-c_{s f 2}\left(\dot{z}-\dot{z}_{t 2}-\right.$ $\left.L_{f} \cdot \dot{\theta}_{2}+L_{l} \cdot \dot{\theta}_{1}\right)-c_{s r 1}\left(\dot{z}-\dot{z}_{t 3}+L_{r e} \cdot \dot{\theta}_{2}+L_{r i} \cdot \dot{\theta}_{1}\right)-c_{s r 2}\left(\dot{z}-\dot{z}_{t 4}+L_{r e} \cdot \dot{\theta}_{2}-L_{l} \cdot \dot{\theta}_{1}\right)+$ $k_{p}\left(z_{b}-z+L_{h 1} \cdot \theta_{2}+L_{h 2} \cdot \theta_{1}\right)+c_{p}\left(\dot{z}_{b}-\dot{z}+L_{h 1} \cdot \dot{\theta}_{2}+L_{h 2} \cdot \dot{\theta}_{1}\right)$

$\sum M=I_{y y} \cdot \ddot{\theta}_{2}$ (Pitching) (Sprung mass)

$I_{y y} \cdot \ddot{\theta}_{2}=k_{s f 1}\left(z-z_{t 1}-L_{f} \cdot \theta_{2}-L_{r i} \cdot \theta_{1}\right) L_{f}+k_{s f 2}\left(z-z_{t 2}-L_{f} \cdot \theta_{2}+L_{l} \cdot \theta_{1}\right) L_{f}-k_{s r 1}\left(z-z_{t 3}+\right.$ $\left.L_{r e} \cdot \theta_{2}+L_{r i} \cdot \theta_{1}\right) L_{r e}-k_{s r 2}\left(z-z_{t 4}+L_{r e} \cdot \theta_{2}-L_{l} \cdot \theta_{1}\right) L_{r e}+c_{s f 1}\left(\dot{z}-\dot{z}_{t 1}-L_{f} \cdot \dot{\theta}_{2}-L_{r i} \cdot\right.$

$\left.\dot{\theta}_{1}\right) L_{f}+c_{s f 2}\left(\dot{z}-\dot{z}_{t 2}-L_{f} \cdot \dot{\theta}_{2}+L_{l} \cdot \dot{\theta}_{1}\right) L_{f}-c_{s r 1}\left(\dot{z}-\dot{z}_{t 3}+L_{r e} \cdot \dot{\theta}_{2}+L_{r i} \cdot \dot{\theta}_{1}\right) L_{r e}-c_{s r 2}\left(\dot{z}-\dot{z}_{t 4}+L_{r e} \cdot\right.$ $\left.\dot{\theta}_{2}-L_{l} \cdot \dot{\theta}_{1}\right) L_{r e}-k_{p}\left(z_{b}-z+L_{h 1} \cdot \theta_{2}+L_{h 2} \cdot \theta_{1}\right) L_{h 1}-c_{p}\left(\dot{z}_{b}-\dot{z}+L_{h 1} \cdot \dot{\theta}_{2}+L_{h 2} \cdot \dot{\theta}_{1}\right) L_{h 1}$ $\sum M=I_{x x} \cdot \ddot{\theta}_{1}$ (Rolling) (Sprung mass)

$I_{x x} \cdot \ddot{\theta}_{1}=k_{s f 1}\left(z-z_{t 1}-L_{f} \cdot \theta_{2}-L_{r i} \cdot \theta_{1}\right) L_{r i}-k_{s f 2}\left(z-z_{t 2}-L_{f} \cdot \theta_{2}+L_{l} \cdot \theta_{1}\right) L_{l}+k_{s r 1}\left(z-z_{t 3}+\right.$ $\left.L_{r e} \cdot \theta_{2}+L_{r i} \cdot \theta_{1}\right) L_{r i}-k_{s r 2}\left(z-z_{t 4}+L_{r e} \cdot \theta_{2}-L_{l} \cdot \theta_{1}\right) L_{l}+c_{s f 1}\left(\dot{z}-\dot{z}_{t 1}-L_{f} \cdot \dot{\theta}_{2}-L_{r i} \cdot\right.$

$\left.\dot{\theta}_{1}\right) L_{r i}-c_{s f 2}\left(\dot{z}-\dot{z}_{t 2}-L_{f} \cdot \dot{\theta}_{2}+L_{l} \cdot \dot{\theta}_{1}\right) L_{l}+c_{s r 1}\left(\dot{z}-\dot{z}_{t 3}+L_{r e} \cdot \dot{\theta}_{2}+L_{r i} \cdot \dot{\theta}_{1}\right) L_{r i}-c_{s r 2}\left(\dot{z}-\dot{z}_{t 4}+\right.$ $\left.L_{r e} \cdot \dot{\theta}_{2}-L_{l} \cdot \dot{\theta}_{1}\right) L_{l}-k_{p}\left(z_{b}-z+L_{h 1} \cdot \theta_{2}+L_{h 2} \cdot \theta_{1}\right) L_{h 2}-c_{p}\left(\dot{z}_{b}-\dot{z}+L_{h 1} \cdot \dot{\theta}_{2}+L_{h 2} \cdot \dot{\theta}_{1}\right) L_{h 2}$

$\sum F_{z}=m_{t f 1} \cdot \ddot{z}_{t f 1}$ (Front right wheel) (Unsprung mass)

$m_{t f 1} \cdot \ddot{z}_{t f 1}=k_{s f 1}\left(z-L_{f} \cdot \theta_{2}-L_{r i} \cdot \theta_{1}-z_{t f 1}\right)+k_{t f 1}\left(-z_{t f 1}+z_{1}\right)+c_{s f 1}\left(\dot{z}-L_{f} \cdot \dot{\theta}_{2}-L_{r i} \cdot \dot{\theta}_{1}-\right.$

$\left.\dot{z}_{t f 1}\right)+c_{t f 1}\left(-\dot{z}_{t f 1}+\dot{z}_{1}\right)$

$\sum F_{z}=m_{t f 2} \cdot \ddot{z}_{t f 2}$ (Front left wheel) (Unsprung mass)

$m_{t f 2} \cdot \ddot{z}_{t f 2}=k_{s f 2}\left(z-L_{f} \cdot \theta_{2}+L_{l} \cdot \theta_{1}-z_{t f 2}\right)+k_{t f 2}\left(-z_{t f 2}+z_{2}\right)+c_{s f 2}\left(\dot{z}-L_{f} \cdot \dot{\theta}_{2}+L_{l} \cdot \dot{\theta}_{1}-\right.$

$\left.\dot{z}_{t f 2}\right)+c_{t f 2}\left(-\dot{z}_{t f 2}+\dot{z}_{2}\right)$

$\sum F_{z}=m_{t r 1} \cdot \ddot{z}_{t r 1}$ (Rear right wheel) (Unsprung mass)

$m_{t r 1} \cdot \ddot{z}_{t r 1}=k_{s r 1}\left(z+L_{r e} \cdot \theta_{2}+L_{r i} \cdot \theta_{1}-z_{t r 1}\right)+k_{t r 1}\left(-z_{t r 1}+z_{3}\right)+c_{s r 1}\left(\dot{z}+L_{r e} \cdot \dot{\theta}_{2}+L_{r i} \cdot \dot{\theta}_{1}-\right.$

$\left.\dot{z}_{t f 1}\right)+c_{t r 1}\left(-\dot{z}_{t r 1}+\dot{z}_{3}\right)$

$\sum F_{z}=m_{t r 2} \cdot \ddot{z}_{t r 2}$ (Rear left wheel) (Unsprung mass) 


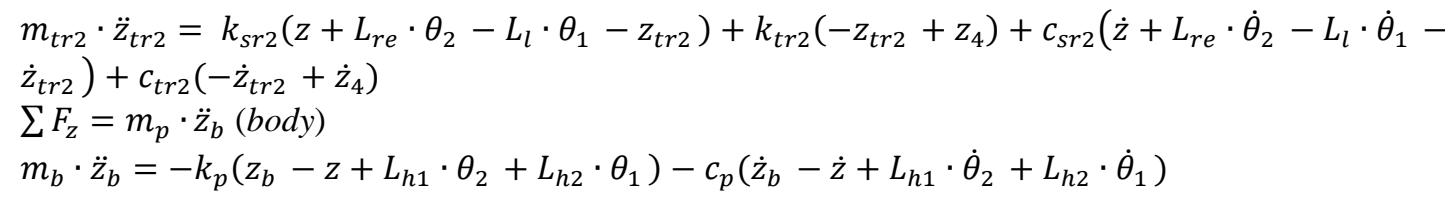

Dimana:

$m_{c} \quad:$ massa total kendaraan

$m_{t f 1} \quad$ : massa ban kanan depan

$m_{t f 2} \quad$ : massa ban kiri depan

$m_{t r 1} \quad$ : massa ban kanan belakang

$m_{t r 2} \quad$ : massa ban kiri belakang

$m_{b} \quad$ : massa pengendara

$I_{y y} \quad$ : inersia $y-y$ axis

$I_{x x} \quad$ : inersia $\mathrm{x}-\mathrm{x}$ axis

$k_{s f 1} \quad$ : kekakuan pegas suspensi kanan depan

$k_{s f 2} \quad:$ kekakuan pegas suspensi kiri depan

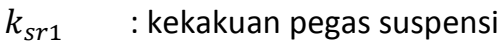
kanan belakang

$k_{s r 2} \quad$ : kekakuan pegas suspensi kiri belakang

$c_{s f 1} \quad$ : konstanta redaman suspensi kanan depan

$c_{s f 2} \quad$ konstanta redaman suspensi kiri depan

$c_{s r 1} \quad$ : konstanta redaman suspensi kanan belakang

$c_{s r 2} \quad$ : konstanta redaman suspensi kiri belakang

$k_{t f 1} \quad:$ kekakuan ban kanan depan

$k_{t f 2} \quad:$ kekakuan ban kiri depan

$k_{t r 1} \quad$ : kekakuan ban kanan belakang

$k_{t r 2} \quad$ : kekakuan ban kiri belakang

$c_{t f 1} \quad$ : konstanta redaman ban kanan depan

$c_{t f 2} \quad$ : konstanta redaman ban kiri depan

$c_{t r 1} \quad$ : konstanta redaman ban kanan belakang

$c_{\text {tr } 2} \quad$ : konstanta redaman ban kiri belakang

$k_{p} \quad$ : kekakuan pelvic pengendara

$c_{p} \quad$ : konstanta redaman pelvic pengendara

Z $\quad$ : perpindahan massa kendaraan

$\dot{Z} \quad$ : kecepatan massa kendaraan

$\ddot{Z} \quad$ : percepatan massa kendaraan

$z_{t f 1} \quad$ : perpindahan massa ban kanan depan

$\dot{z}_{t f 1} \quad$ : kecepatan massa ban kanan depan

$\ddot{z}_{t f 1} \quad$ : percepatan massa ban kanan depan

$z_{t f 2} \quad$ : perpindahan massa ban kiri depan

$\dot{Z}_{t f 2} \quad$ : kecepatan massa ban kiri depan

$\ddot{z}_{t f 2} \quad$ : percepatan massa ban kiri depan

$z_{t r 1} \quad$ : perpindahan massa ban kanan belakang

$\dot{z}_{t r 1} \quad$ : kecepatan massa ban kanan belakang

$\ddot{z}_{t r 1} \quad$ : percepatan massa ban kanan belakang

$z_{\text {tr2 }} \quad$ : perpindahan massa ban kiri belakang

$\dot{z}_{\text {tr } 2} \quad$ : kecepatan massa ban kiri belakang

$\ddot{z}_{t r 2} \quad$ : percepatan massa ban kiri belakang

$z_{1} \quad$ : eksitasi ban kanan depan

$z_{3} \quad$ : eksitasi ban kanan belakang

$Z_{2} \quad$ : eksitasi ban kiri depan

$Z_{4} \quad$ : eksitasi ban kiri belakang

$z_{b} \quad$ : perpindahan massa badan pengendara

$\dot{Z}_{b} \quad$ : kecepatan massa badan pengendara

$\ddot{z}_{b} \quad$ : percepatan massa badan pengendara

$\theta_{1} \quad$ : perpindahan angular massa kendaraan $\mathrm{x}$ axis

$\dot{\theta}_{1} \quad$ : kecepatan angular massa kendaraan $\mathrm{x}$ axis

$\ddot{\theta}_{1} \quad$ : percepatan angular massa kendaraan $\mathrm{x}$ axis

$\theta_{2} \quad$ : perpindahan angular massa kendaraan y axis

$\dot{\theta}_{2} \quad$ : perpindahan angular massa kendaraan y axis

$\ddot{\theta}_{2} \quad$ : perpindahan angular massa kendaraan y

axis 


\subsection{Verifikasi Pemodelan}

Pada proses verifikasi pemodelan, hal yang dilakukan yaitu melakukan perbandingan dengan penelitian serupa yang menggunakan pemodelan half car dengan 1 DOF pengendara. Jika hasil yang didapatkan sama, maka dapat disimpulkan bahwa pemodelan yang dilakukan benar.

\subsection{Pembuatan Eksitasi Gangguan Jalan}

Eksitasi gangguan jalan pada penelitian ini yaitu berupa gelombang sinusoidal, dengan Amplitudo eksitasi $\left(x_{0}\right)$ pada jalan sebesar 0,05 m dengan panjang gelombang $(\lambda)$ sebesar 0,5 $\mathrm{m}$. Gambar 3 menunjukkan ilustrasi bentuk permukaan jalan.

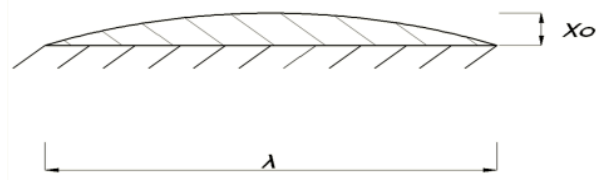

Gambar 3. Profil Eksitasi Jalan

\section{HASIL DAN PEMBAHASAN}

Dengan menggunakan rumusan Root Mean Square dan grafik ISO 2631, maka didapatkan grafik seperti yang ditunjukkan Gambar 4

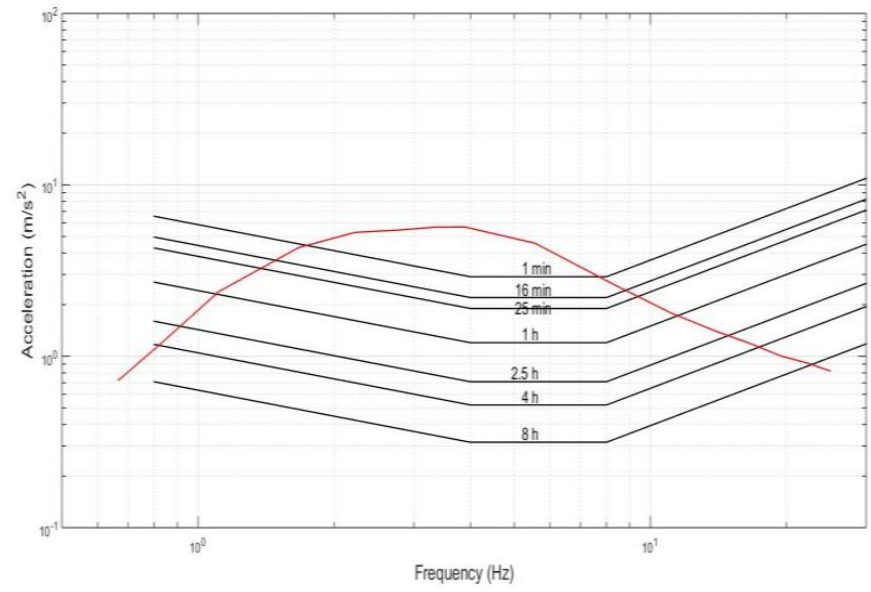

Gambar 4. Percepatan Vertikal Pengendara

Pada Gambar 4 menunjukkan bahwa secara umum kendaraan memiliki tingkat kenyamanan dibawah 1 menit. Akan tetapi, jika dilihat secara terperinci, penggunaan kecepatan kendaraan akan banyak digunakan pada kecepatan 20 - $40 \mathrm{~km} / \mathrm{jam}(11,11$ - 22,22 Hz). Pada kecepatan tersebut, menunjukkan kenyamanan berkendara selama diatas 2,5 jam.

\section{SIMPULAN}

Berdasarkan hasil simulasi didapatkan bahwa pada dengan menggunakan kecepatan konstan antara $20-40 \mathrm{~km} / \mathrm{jam}$, kendaraan akan nyaman dikendarai selama lebih dari 2,5 jam.

\section{DAFTAR PUSTAKA}

[1.] I N Sustantra, B Sampoerno, Teknologi Otomotif, Edisi Kedua, Surabaya : Guna Widya, 2010.

[2.] Bayu E Suprayogi, "Perancangan Ulang dan Analisa Sistem Suspensi Mobil Multiguna Pedesaan dengan Standar Kenyamanan ISO 2631", Institut Teknologi Sepuluh November, Surabaya. 2015.

[3.] Puja P, I N Sutantra, "Analisa Kenyamanan Serta Redesain Pegas Suspensi Mobil Toyota Fortuner 4.0 V6 SR", Jurnal Teknik Mesin ITS, vol. 4, no. 1, pp. 1-6, 2015.

[4.] Reza N Jazar, Vehicle Dynamics Theory and Application, Second Edition, New York : Springer, 2014. 